\title{
Construction Procurement: Modelling Bidders' Learning in Recurrent Bidding
}

\author{
Bee Lan Oo ${ }^{1}$, Florence Yean Yng Ling ${ }^{2}$ and Alexander Soo ${ }^{1}$ \\ ${ }^{1}$ Faculty of Built Environment, University of New South Wales, Australia \\ ${ }^{2}$ Department of Building, National University of Singapore
}

\begin{abstract}
Construction remains a significant area of public expenditure. An understanding of the process of changes in construction pricing, and how the process can be manipulated through the release of bidding feedback information is vital, in order to best design clients' procurement policies. This paper aims to statistically model inexperienced individual bidders' learning in recurrent bidding under partial and full information feedback conditions. Using an experimental dataset, the developed linear mixed model contains three predictor variables, namely: time factor, information feedback conditions, and bidding success rate in the preceding round. The results show nonlinearity and curvature in the bidders' learning curves. They are generally less competitive in time periods after a winning bid with lower average bids submitted by those subjected to full information feedback condition. In addition, the model has captured the existence of heterogeneity across bidders with individual-specific parameter estimates that demonstrate the uniqueness of individual bidders' learning curves in recurrent bidding. The findings advocate for adequate bidding feedback information in clients' procurement design to facilitate learning among contractors, which may in turn lead to increased competitiveness in their bids.
\end{abstract}

Keywords: Construction procurement, bidding, information feedback, learning.

Paper type: Research article

\section{Introduction}

Construction spending by public and private clients tends to be large scale and consequently expensive. An understanding of the process of changes in the price of building work, and how the process can be manipulated through the release of bidding feedback information is vital, in order to best design clients' procurement policies, thereby optimising future procurement strategies. Information feedback in recurrent bidding is an important design variable in optimal procurement design, since it can substantially affect outcomes, even when the feedback has no strategic information value (Ockenfels and Selten, 2005). Milgrom and Weber (1982) pointed out that feedback information never has a negative value to the decision-maker. At worst, irrelevant bidding feedback information can be ignored by contractors.

There is strong empirical evidence of systematic variations in bids over time (e.g., McCaffer and Pettitt, 1976; de Neufville, Lesage and Hani, 1977; Fu, Drew and Lo, 2002; Oo, Lo and Lim, 2012), suggesting that contractors learn from their experiences. In examining a bidding dataset of public sector projects covering six years, Fu, Drew and Lo (2002) found that experienced contractors who bid more frequently are more competitive than contractors who bid only

\footnotetext{
Copyright: Construction Economics and Building 2015. (C) 2015 Bee Lan Oo, Florence Yean Ying Ling and Alexander Soo. This is an Open Access article distributed under the terms of the Creative Commons Attribution 4.0 Unported (CC BY 4.0) License (https://creativecommons.org/licenses/by/4.0/), allowing third parties to copy and redistribute the material in any medium or format and to remix, transform, and build upon the material for any purpose, even commercially, provided the original work is properly cited and states its license.
}

Citation: Oo, B.L., Ling, F.Y.Y., and Soo, A. 2015. Construction procurement: modelling bidders' learning in recurrent bidding, Construction Economics and Building, 15(4), 16-29. DOI: http://dx.doi.org/10.5130/AJCEB.v15i4.4653

Corresponding author: Bee Lan Oo; Email - bee.oo@unsw.edu.au

Publisher: University of Technology Sydney (UTS) ePress 
occasionally. Cason and Friedman (1999) state that variations in bids are a result of a learning and adjustment process (i.e. adaptive learning) in order to reach an optimum price. Contractors tend to optimize their bids in recurrent bidding with positive reviews of previous bidding results (Fu, Drew and Lo, 2002). Similarly, Kagel and Levin (2002) suggest that bidders learn from their experiences, and that making profits, losses or being unsuccessful will result in changes to their bid prices. Thus, bidding feedback information plays a vital role to enable learning among contractors in recurrent bidding.

This paper aims to statistically model inexperienced individual bidders' learning in recurrent bidding under two different information feedback conditions, namely partial information feedback condition (winning bid and the identity of the winning bidder) and full information feedback condition (all bids and the identity of the bidder making each bid). The specific objectives are to: investigate whether inexperienced bidders become more competitive over time through recurrent bidding; study whether inexperienced bidders reach a steady-state as they learn through recurrent bidding; examine the role of information feedback on inexperienced bidders' learning; and explore the learning trends of inexperienced bidders in recurrent bidding. Using a linear mixed model, the notion of heterogeneity is considered in the statistical modelling attempt to capture the existence of heterogeneity across individual bidders, demonstrating the uniqueness of individual bidders' learning in recurrent bidding. It is noted that hitherto, no similar attempt has been made to derive empirically individual-specific parameter estimates that ascertain specific types of learning curves of individual bidders in response to different information feedback conditions. The purpose of undertaking this study is to advance our understanding of the process of changes in the construction pricing, and how the process can be manipulated through the release of bidding feedback information. The findings clearly have implications on clients' procurement policies.

\section{Information Feedback and Learning in Construction Bidding}

There is a collection of studies in conventional economics that examined the effect of different bidding information feedback conditions on bidders' bidding behavior via experimental settings. These experiments were designed in two main settings, namely ascending first-price sealed-bid auction (e.g. Neugebauer and Selten, 2006; Engelbrecht-Wiggans and Katok, 2008; Neugebauer and Perote, 2008) and descending first-price sealed-bid auction (e.g. Dufwenberg and Gneezy, 2002; Esponda, 2008). They provide a substantial amount of evidence that varying information feedback conditions affect bidders' competitiveness to different degrees, thereby affecting the revenues of those accepting bids to buy or sell.

In construction bidding, many codes of bidding procedure recommend clients provide contractors with bidding feedback information (e.g. Ministry of Finance, 2005; New South Wales Government, 2005). The information feedback conditions adopted by construction clients can be broadly classified into full, partial and no information (Oo, Abdul-Aziz and Lim, 2011). In the full information feedback condition, bidders were informed at the end of each bidding competition about all bids and the identity of the bidder making each bid. In the partial information feedback condition, bidders were provided only with the winning bid and the identity of the winning bidder at the end of each bidding competition. However, in many cases, clients do not provide feedback information or provide insufficient feedback to contractors (Drew and Fellows, 1996). Despite the fact that the exercise to collect historical bids is both time consuming and expensive to undertake (Lowe and Skitmore, 2006) it has been reported that contractors obtained historic bidding data from a variety of sources, including: competitors, subcontractors, friendly acquaintances, suppliers and newspapers (Park and Chapin, 1992; Drew and Fellows, 1996). This can be explained because contractors have to rely on effective pricing methods in order to translate potential business into reality for long-term survival of their firms, 
this inevitably involves effective utilization of bidding feedback information towards winning jobs with high profit potential (Soo and Oo, 2010). They use historic bidding dataset for their own purpose wherever it seems fit, including (Drew and Fellows, 1996; Lo, Drew and Fu, 2000; Runeson, 2000): (i) for analyzing the prevailing market conditions; (ii) for analyzing the competitiveness of their cost estimates; (iii) for deciding on whether or not to bid for future projects; (iv) for determining mark-up for future projects; (v) for analyzing their bidding performance; and (vi) for analyzing bidding performance of their competitors. Kortanek, Sodeni and Sodaro (1973) noted that a bidder's bidding strategy that reflects its bidding behavior at any time is a direct product of learning, governing the bidder's competitiveness. Fu, Drew and Lo (2004) proposed a conceptual framework of learning in recurrent construction bidding in which a contracting firm is seen as an interpretation system. The learning process activates the interpretation process that transforms a flow of data (i.e., previous bidding results and data derived from completed and ongoing projects) into information, and that interpreted information is incorporated into next bidding decision to enhance competitiveness. It is recognized that current and past project information would have an impact on contractors' bidding decisions, the focus of this study is, however, on the effect of previous bidding results on inexperienced bidders' learning.

\section{The Notion of Heterogeneity}

The bidder homogeneity assumption, i.e., all bidders are homogenous and behaving collectively and consistently in a similar statistical manner (Skitmore, 1991) has been adopted in considerable large sets of statistical bidding models, which can be attributed to data limitations that do not allow the application of heterogeneity approach to modelling (Runeson and Skitmore, 1999). However, of the little empirical research to date aimed at testing the tenability of this assumption, several studies have reported the existence of heterogeneity across bidders (e.g. Skitmore, 1991; Oo, Drew and Lo, 2007; 2008; 2010a). In modelling the extent to which individual bidders' decision to bid and mark-up decisions are affected by a given set of project decision making environment factors, Oo, Drew and Lo's (2007; 2008; 2010a) statistical models comprise individual-specific parameter estimates for each individual bidders in the samples involved. It follows that the heterogeneity puts contractors at varying predispositions for bidding decisions with bidding strategies varying from contractor to contractor in achieving individual firms' pricing objectives (Oo, Drew and Lo, 2010a). Contractors have placed different degrees of preference and sensitivity toward factors affecting their bidding decisions as reported in many survey studies (e.g. Shash, 1993; Ling, 2005; Egemen and Mohamed, 2007). As an illustration of the notion of heterogeneity, Oo, Drew and Lo (2010a) used an example of bidding competition for a school project. Some contractors will have lower cost estimates and bid consistently low for a school project, if for no other reason than because of differentiable resources and capabilities, mainly through the learning curve in performing this type of project regularly. This may explain in part the variations in contractors' bids and so the bidding performance differs among contractors. The present work adopts a heterogeneity approach to modelling specific types of learning curves of individual bidders in response to different information feedback conditions.

\section{Knowledge Gap}

Recently, experimental studies that specifically focus of the effect of bidding feedback information on inexperienced bidders' bidding behavior were reported (Soo and Oo, 2010; Oo, Abdul-Aziz and Lim, 2011; Oo, Ling and Soo, 2014). Their findings provide a strong indication of continuous learning among the bidders. Oo, Abdul-Aziz and Lim (2011) have also examined the extent to which the bidders' bidding trends agree with the behavioral patterns proposed by learning direction theory postulated by Selten and Stoecker (1986) and Selten and Buchta (1999). 
In relation to capacity utilization, they found that bidders with partial bidding feedback information are more likely to vary their bids as indicated by the theory over a time period consisting ten bidding rounds. Fu, Drew and Lo (2004) proposed a hypothetical learning curve in recurrent bidding, which consists of start-up and steady-state learning phases. In a start-up learning phase, bidders are expected to learn rapidly as demonstrated by increased bidding competitiveness in initial bidding attempts. For a steady learning phase, the learning curve is in a plateau pattern, indicating that bidders have obtained their optimal bidding strategy. However, their results only partially support the existence of rapid learning during the start-up phase among the inexperienced bidders (newly listed contractors), while experienced bidders in their sample were in a steady phase of learning demonstrated by their behavioral regularity. It is noted that their analysis was based on graphical plots, with no attempt to quantify the effect of time factor on bidders' learning over time. Similarly, Skitmore and Runeson (2006) focused on variations in bids over time in testing the stationarity assumption of bidding models, but not on the quantification of effect of time on contractors' bid prices. This study was undertaken to fill this knowledge gap by presenting a statistical model on individual bidders' learning over time in recurrent bidding in response to the two information feedback conditions - partial and full.

\section{Research Hypothesis}

The hypotheses that formed the foundation for this empirical investigation are set out below:

H1: Inexperienced bidders become more competitive over time through learning in recurrent bidding.

H2: The learning curve of inexperienced bidders in recurrent bidding consists of start-up and steady-state learning phases.

H3: The partial and full information feedback conditions have an impact on inexperienced bidders' learning in recurrent bidding.

H4: There is significant heterogeneity across inexperienced individual bidders' learning in recurrent bidding.

\section{Research Method}

A large study on the effect of different information feedback conditions on inexperienced bidders' competitiveness in recurrent bidding has been conducted. An experimental research design was used because there are many possible factors affecting contractors' bidding decisions, and only an experimental research design would allow for control over the variables, something that would not have been possible using field data. Moreover, it would have been difficult to obtain the necessary data for projects of different sizes and types along with different information feedback conditions. Oo, Ling and Soo (2014) reported on the bidders' bidding behavior in terms of bid competitiveness, bid-spread, and the effect of cost estimate accuracy under full and partial information feedback conditions. This study reports on the bidders' learning in recurrent bidding in response to the two information feedback conditions.

\section{Dataset}

The dataset from Oo, Ling and Soo (2014) was used for the modelling attempt in the present work. It is a panel dataset consisting of 1349 bids obtained through a controlled research situation via an experimental design that used information feedback as the experiment treatments $(\mathrm{P}=$ partial information feedback; $\mathrm{F}=$ full information feedback). The inexperienced (student) subjects in their experiment were randomly assigned to one of two treatments with 10 bidding rounds (two rounds per week) per treatment. Each of the two primary groups ( $\mathrm{P}$ and $\mathrm{F}$ ) were 
further split into 12 subgroups (five students in each subgroup) to simulate a bidding competition of 12 competing bidders $(N=12)$. In each bidding round, the subjects were invited to bid for six hypothetical general building projects (a total of 60 hypothetical projects comprising schools and institutional buildings). Apart from the project information (location, duration, client and contract type), the subjects were also given an unbiased cost estimate for each hypothetical project, which is the net project construction cost (i.e., total of direct cost estimate + site overheads). They were required to decide which project to bid for, and submit their bids to the experiment coordinator via emails. The general instruction to the subjects was that their ultimate aim was to survive and make the most profit in a competition where the lowest bidder wins the job. It is worth noting that identical hypothetical projects and unbiased cost estimates were used for both $\mathrm{P}$ and $\mathrm{F}$ treatments to enable direct comparisons between the two groups.

The suitability of the dataset is supported by three reasons that allow us to test the research hypotheses as unambiguously as possible. First, the use of inexperienced student subjects in the experiment enables the examination of true learning behavior of bidders. Dyer, Kagel and Levin (1989) pointed out that the examination is only possible with inexperienced bidders because experienced bidders "carry" industry experience and known rule-of-thumbs to a simulated experiment, causing data contamination. Second, Oo, Ling and Soo (2014) conducted the experiment in an environment in which experiences (learning) could be gained and bankruptcy could occur. Each subject in their experiment was 'given' a start-up capital of $\mathbf{S} \$ 400,000$ (S\$1 US\$0.80) to sustain the operating expenses (capital charges, general overheads, etc.) estimated at S $\$ 40,000$ per bidding round, and profit or loss was generated for each hypothetical project they won. The profit or loss was determined by deducting a randomly assigned final cost (ranging from $90 \%$ to $110 \%$ of unbiased cost estimate) from the winning bid. In this way, subjects that accrued losses that exhausted their start-up capital and accumulated profits would be declared bankrupt and no longer allowed to bid. Similarly, failure to win job to pay for operating expenses would eventually force the subjects out of the 'market'- a reality in the construction industry. Also, the subjects were given limited working capacity and would have to incur a cost penalty (for the added costs of securing additional resources) if they had to operate beyond their optimal capacity (maximum five projects on hand at a time). After each round, subjects in both treatments were informed privately of their capacity utilization and the profit or loss generated from the projects they won in previous rounds.

Lastly, the dataset was subjected to the statistical tests in Oo, Ling and Soo (2014) on seriousness of the student subjects' bids and randomness of subject selection in the experimental setting. Their test results provided strong evidence that the quality of the experimental data was not being jeopardized by the use of student subjects.

\section{Development of the linear mixed model}

Linear mixed model (LMM), an extension of the ordinary least squares (OLS) regression analysis, was used to model the individual bidders' learning in recurrent bidding. Similar to OLS regression analysis, the model assumes a continuous dependent variable is linearly related to a set of independent variables, but requires extra work in model specification and subsequent goodness-of-fit check (see Verbeke and Molenberghs (2000) for the model building process). The underlying premise of LMM is that some subset of the regression coefficients (the random effects) varies randomly from one individual (subject) to another, thereby accounting for heterogeneity in the population. It follows, therefore, there are essentially two components that make up a LMM, namely the fixed effects, $\beta$ 's and the random effects, $b$ 's. The fixed effects is the population mean profile that assumed to be shared by all individual bidders in the population, and the random effects that are subject-specific effects that are unique to individual bidders. The random effects are incorporated in the model to accommodate between-subject variability, in 
which individuals in the population are assumed to have their own subject-specific mean profile. Oo, Drew and Lo (2010a) and Oo, Drew and Runeson (2010b) used the same modelling approach to examine individual bidders' mark-up profiles in response to factors affecting their bidding decisions (i.e. with the parameter estimates that varied across individual bidders). Such estimates are of interest in the present analysis to examine subject-specific learning profiles in recurrent bidding.

Learning, expressed in the form of subjects' competitiveness, was taken as the dependent variable in the LMM. The unbiased cost estimate provides a common baseline and the measure of subjects' competitiveness is to express each bid as a percentage above the unbiased cost estimate:

$$
M U P=100\left(x_{i}-x\right) / x
$$

Where: MUP is the mark-up percentage, $x_{i}$ is the $i^{\text {th }}$ subject's bid and $x$ is the unbiased cost estimate for each hypothetical project. Lower percentage values indicate greater competitiveness since the lowest bidder wins at the lowest bid price, and vice versa.

There are four independent variables in the LMM. Time points $(t)$, as indicated by the bidding round numbers (1 to 10), is a quantitative independent variable. A quadratic term for this variable $\left(t^{2}\right)$ is added to allow for nonlinear change in subject-specific learning curves. The information feedback group $(G)$ is a categorical independent variable which requires the use of dummy variables, where $G=0$ for group $\mathrm{P}$ and $G=1$ for group F. Taking into account the experimental design in which the subjects were given feedback information about their performance in previous rounds, two additional independent variables have been considered in the modelling attempt to better reflect the subjects' learning in recurrent bidding. They are: (i) current workload $(W)$ that indicates the subjects' capacity utilization, where $W=0$ if they were working below optimal capacity (number of projects on hand $\leq 4$ ) and $W=1$ if they were working at or beyond optimal capacity (number of projects on hand $\geq 5$ ) at a particular time point, and (ii) bidding success in preceding round ( $S$ ). The latter is given by $S=0$ if the subjects were unsuccessful and $S=1$ if the subjects were successful in winning a job(s) in the preceding round. The decision to include these variables is supported by the empirical evidence discussed above (e.g. Fu, Drew and Lo, 2002; Kagel and Levin, 2002; Oo, Abdul-Aziz and Lim, 2011). It should be noted that the profit or loss on winning bids has not been included in the modelling attempt because this feedback information was not available from round to round and depend on the project duration. All the hypothetical projects have minimum project duration of two rounds in Oo, Ling and Soo's (2014) experiment, and the profit or loss statement was not available until the completion of a project (i.e. a minimum lapse of two bidding rounds).

To fix ideas, the LMM for modelling the MUP with intercepts and slopes that vary randomly across the $i^{\text {th }}$ subject at the $j^{\text {th }}$ measurement occasion $\left(j=1, \ldots n_{i}, n_{i}\right.$ is the number of bidding attempts per subject) has given rise to a linear prediction equation in the form of:

$$
\operatorname{MUP}_{i j}=\left(\beta_{0}+b_{0 i}\right)+\left(\beta_{1}+b_{1 i}\right) t_{i j}+\left(\beta_{2}+b_{2 i}\right) t^{2} i j+\left(\beta_{3}+b_{3 i}\right) G_{i j}+\left(\beta_{4}+b_{4 i}\right) W_{i j}+\left(\beta_{5}+b_{5 i}\right) S_{i j}
$$

Where: parameters $\beta_{0}, \ldots, \beta_{5}$ are the population-average structure (i.e., the fixed effects that are shared for all bidders), whereas other parameters (i.e., $b_{0 j}, \ldots, b_{5 .}$ ) are subject-specific effects (i.e., the random effects that are unique to each subject). In this LMM, fixed effects, $\beta$ and random effects, $b$ are connected to each other, so that any observable effect is a combination of the two. For example, $\left(\beta_{1}+b_{1 i}\right)$ is the $i^{\text {th }}$ subject's slope, or rate of change in MUP (leaning) over time. It demonstrates the extension of the model to determine individual subjects' characteristics $\left(b_{0}, \ldots, b_{5 i}\right)$ that relate to differences in MUP. 


\section{Results and Discussion}

The statistical inferences using $t$, F-, Wald- and likelihood ratio-tests in the mixed effects model building process show that the best-fit LMM containing four predictor variables, namely: (i) time $(t)$; (ii) time squared $\left(t^{2}\right)$; (iii) information feedback group $(G)$; and (iv) bidding success rate in preceding round $(S)$ as given below:

$$
M U P_{i j}=\left(\beta_{0}+b_{0 i}\right)+\left(\beta_{1}+b_{1 i}\right) t_{i j}+\left(\beta_{2}+b_{2 i}\right) t^{2} i j+\left(\beta_{3}\right) G_{i j}+\left(\beta_{5}+b_{5 i}\right) S_{i j} \quad \text { (Eq. 3) }
$$

Comparing Eq. 2 and 3, it can be seen that current workload (W) was not found to be significant $\left(\beta_{4}+b_{4 i}\right)$, and similarly for the random effect of information feedback group $\left(b_{3 i}\right)$. The latter indicates that the variability between subjects is not significantly affected by their information feedback groupings. Table 1 contains the parameter estimates for the model fixed effects and the corresponding 95\% confidence intervals. Although the information feedback group $(G)$ is not significantly different from zero at $p<0.05(p=0.06)$, the corresponding effect has not been removed from the best-fit LMM for two reasons. First, the null hypothesis that a simpler model without information feedback group $(G)$ parameter is acceptable at $p<0.05$ is rejected based on a likelihood ratio-test, indicating the best-fit model provides an adequate description of the dataset. Second, a point estimate for the average MUP level in the two information feedback groups may be of interest to reader. All the other fixed effects are significant at $p<0.05$.

Table 1: Parameter estimates for the fixed effects of the best-fit LMM

\begin{tabular}{lllllll}
\hline & & & & & \multicolumn{2}{c}{$95 \%$ confidence interval } \\
\cline { 6 - 7 } Parameter & Estimate & Std. Error & $\mathrm{t}$ & Sig. & $\begin{array}{l}\text { Lower } \\
\text { bound }\end{array}$ & $\begin{array}{c}\text { Upper } \\
\text { bound }\end{array}$ \\
\hline Intercept, $\beta_{0}$ & 9.095 & 1.290 & 7.051 & 0.000 & 6.428 & 11.761 \\
Time, $\beta_{1}$ & -1.370 & 0.464 & -2.952 & 0.007 & -2.333 & -0.408 \\
Time x time, $\beta_{2}$ & 0.102 & 0.037 & 2.757 & 0.011 & 0.025 & 0.178 \\
Group, $\beta_{3}$ & -0.788 & 0.419 & -1.882 & 0.060 & -1.663 & 0.087 \\
Success, $\beta_{5}$ & 1.347 & 0.501 & 2.691 & 0.014 & 0.303 & 2.391 \\
\hline
\end{tabular}

Table 2 contains the random effects estimation (or known as empirical 'Best Linear Unbiased Predictor' (BLUP)) for individual bidders. All the subjects were assigned each a code to preserve anonymity. For subjects in the partial information feedback group, the coding starts with letter $P$ and followed by the numbering from one to twelve. On the other hand, letter $F$ is used for subjects in the full information feedback group, i.e. F1 to F12 corresponding to the twelve subjects. It can be seen that the empirical BLUPs are of both positive and negative signs, indicating that the individual bidders' responses to the predictor variables are either above or below the population mean. For example, the intercept for subject F1 of negative sign $\left(b_{01}=-\right.$ 5.951) indicates that the 'true' MUP of this subject is below of the population mean based on the model parameter $\left(\beta_{0}+b_{0 i}\right)$ in Eq. 3. The term 'true' MUP is used to remind reader that this $b_{0 i}$ is a parameter in the LMM since the actual MUP when other parameters in the model are zero is not observed and not estimable. Similarly, subject F1's responses (slopes) to the time $\left(b_{11}=2.728\right)$ and time squared $\left(b_{21}=-0.211\right)$ are of opposite signs, which indicate the corresponding effects are either above or below the population mean (see illustrative plot of subject-specific predicted MUP profile of Subject F1 in Figure 2).

We first examine the fixed effects estimates, the model for the population mean, averaged over the distribution of the subject-specific random effects, is given by: 


$$
E\left(M U P_{i j}\right)=\beta_{0}+\beta_{1} t_{i j}+\beta_{2} t^{2} i j+\beta_{3} G_{i j}+\beta_{5} S_{i j}
$$

It appears that all the predictor variables have the expected signs. The population mean MUP is associated with a decrease of $1.37 \%$ over each time point, i.e., the bidders become more competitive in recurrent bidding through learning. This MUP trend is, however, offset by a nonlinear change of $0.102 \%$ over each time point. It provides evidence of nonlinearity and curvature in the bidders' learning curves. Figure 1 shows the predicted mean MUP profiles over ten time points using Eq. 4 according to bidding success in preceding round $(S=0$ and $S=1)$. It can be clearly seen that the mean MUP profiles for subjects in both information feedback groups decrease over time before an increasing trend for the last few bidding rounds. Time point seven $(t=7)$ is the turning point of the mean MUP profiles for subjects in both information feedback groups. This suggests that the subjects have submitted higher bids that might provide better payoffs - to maximize profits - after a start-up learning period. Another possible explanation for the increasing MUP trends after time point seven is that the subjects would have high current workload and thus bid higher since they were with less spare capacity. The evidence, however, suggests that changes in situational conditions of the bidders (e.g., current workload, resource capacity, financial standing) at the time of bidding, and that the bidders were in a continual process of learning. Therefore, hypothesis $H 1$ that suggests inexperienced bidders become more competitive over time through learning in recurrent bidding is partially supported, given the existence of less competitive MUP trends after a period of time. $\mathrm{H} 2$ is also partially supported since there is an absence of steady-state learning phase in the mean MUP profiles for subjects in both information feedback groups. The less competitive bids after a start-up learning phase suggest that the bidders had yet to reach their optimal bidding strategy with a plateau pattern that characterizes a steady-state learning phase. This finding does not conform to the learning curve postulated in Fu, Drew and Lo (2004) which may be due to the short time frame of the experimental dataset of only ten time points, over 5 weeks.

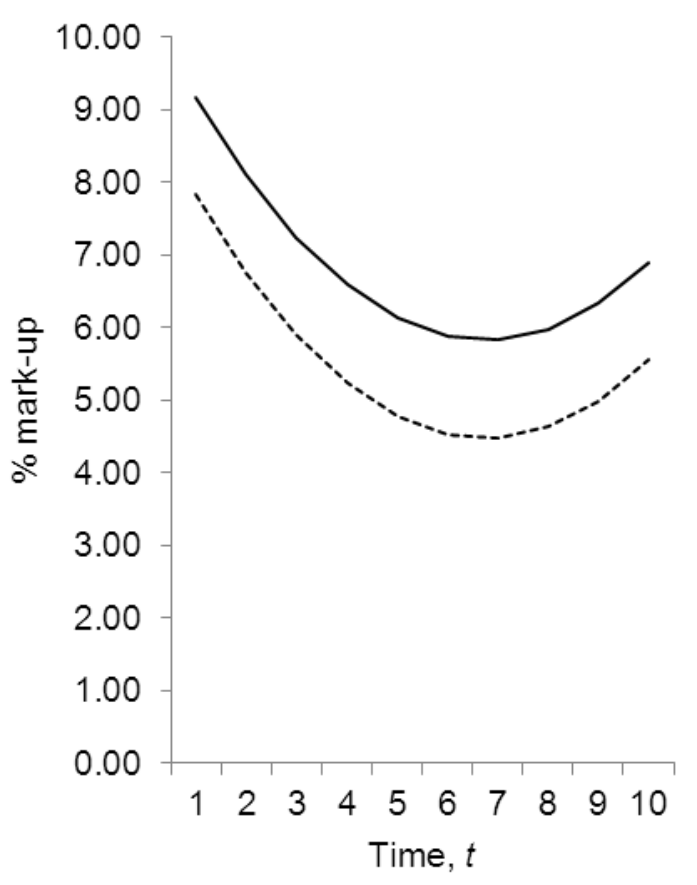

(a) Partial information feedback

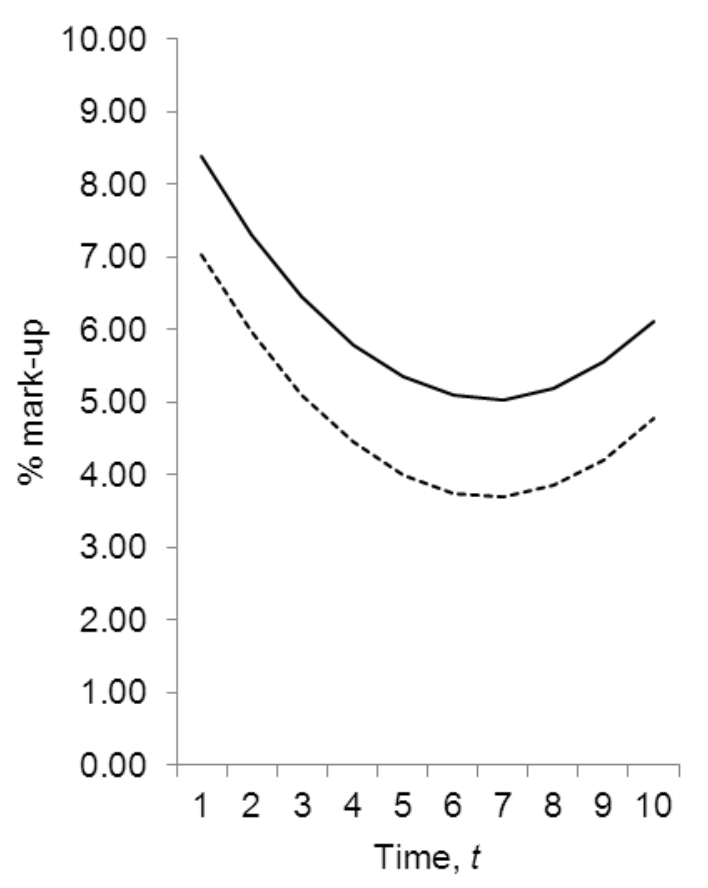

(b) Full information feedback

Figure 1: Population-average predicted profiles over time according to information feedback conditions and bidding success ( $S=1$ if successful: solid lines, and $S=0$ if unsuccessful: short dashes) 
Table 2: Empirical BLUPs for the random effects of the best-fit LMM

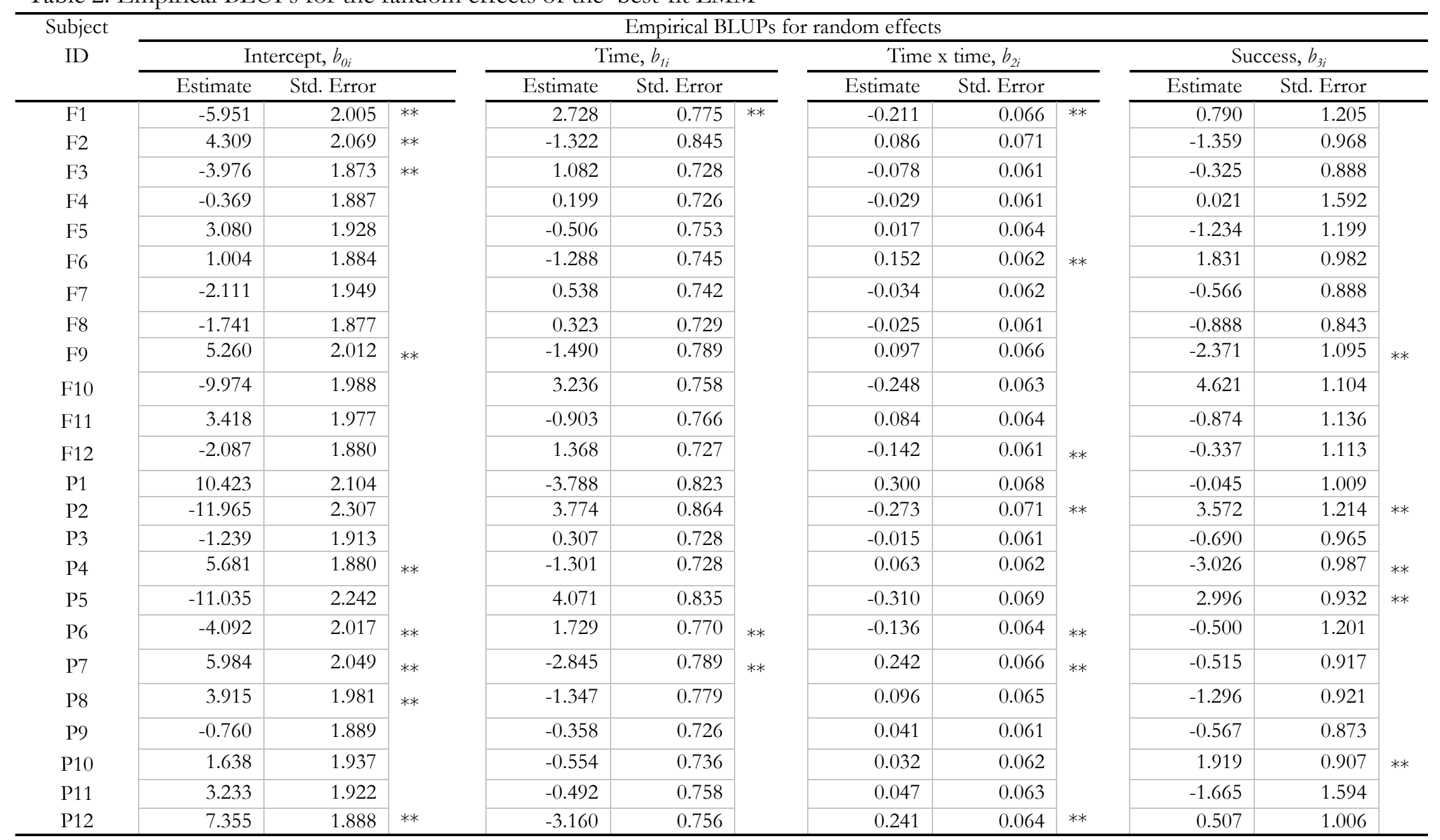

** significant at $p<0.05$ 
Next, the subjects in full information feedback group are generally more competitive that those in the partial information feedback group as demonstrated by a decrease of $0.788 \%$ in the predicted mean MUP for full information feedback group. The bidding feedback information plays a role in the bidders' learning as demonstrated by higher bidding competitiveness for bidders in full information feedback group, similar to that of Soo and Oo (2010). This suggests that the considerably large amount of feedback information with 12 competing bidders in each bidding round of six hypothetical projects (i.e. a set of 72 bids and bidder identities) does not appear to retard the bidders' learning. The subjects in full information feedback group had made use of the bidding feedback information and were able to bid competitively. Thus, $\mathrm{H} 3$ that suggests the two information feedback conditions have an impact on inexperienced bidders' learning in recurrent bidding is supported. Also, the subjects had bid higher with an increase of $1.347 \%$ in the predicted mean MUP if they were successfully in winning a job(s) in the preceding round. It is noted that the positive effect of bidding success in the preceding round is similar to that of McCaffer and Pettitt (1976) and Oo, Lo and Lim (2012), where bidders are generally less competitive in time periods after a winning bid.

To examine both the fixed and random effects estimates of the model, the empirical BLUPs for individual subjects (Table 2) were substituted into Eq. 3 to obtain the mean MUP profiles over time for each individual subjects. Figure 2 shows the illustrative plots of the predicted individual mean MUP profiles for Subjects P6 and P7 in partial information feedback group, and Subjects F1 and F9 in full information feedback group for scenario $S=1$ (i.e., won at least one job in preceding bidding round). The predicted population-average MUP profiles were imposed for illustrative purposes. These subjects were selected for the illustrative plots because the majority of their empirical BLUPs are significant at $p<0.05$. It can be clearly seen that the direction of the mean MUP profiles for Subjects P7 and F9 have not deviated significantly from the respective population-average MUP profiles. However, their mean MUP profiles are steeper over time, particularly for Subject P7. This is mainly due to the larger adjustment in the subjects' MUP over each time point as indicated by the higher empirical BLUPs for the slope for time factor (i.e., -2.845 for P7, -1.490 for F9). The mean MUP profiles for Subjects P6 and F1 are, however, of opposite trend compared to the respective population-average MUP profiles. That is, their mean MUP profiles increase over time and follow by a decreasing trend after a turning point. A possible explanation is that Subjects P6 and F1 were successfully in winning jobs in earlier bidding rounds (i.e., with high current workload) and submitted less competitive bids in subsequent rounds, and that they started to bid competitively for the last few bidding rounds when there was a need for more jobs. Overall, the empirical BLUPs and the illustrative plots clearly demonstrate the need to consider subject-specific effects in response to the predictor variables in examining individual bidders' learning in recurrent bidding. There is significant heterogeneity across inexperienced individual bidders' learning in recurrent bidding (which is reflected in the varying individual bidders' intercepts and slopes). The learning curve of each individual bidder is unique. Hypothesis $\mathrm{H} 4$ is thus supported. The existence of heterogeneity across bidders in modelling their bidding behavior were also detected in Oo, Drew and Lo (2007; 2008; 2010a), Oo, Drew and Runeson (2010b) and Oo, Lo and Lim (2012), suggesting that ignoring individual effects or heterogeneities that exist in the population could lead to inconsistent and meaningless estimates of interesting parameters (Hsiao, 2003). 

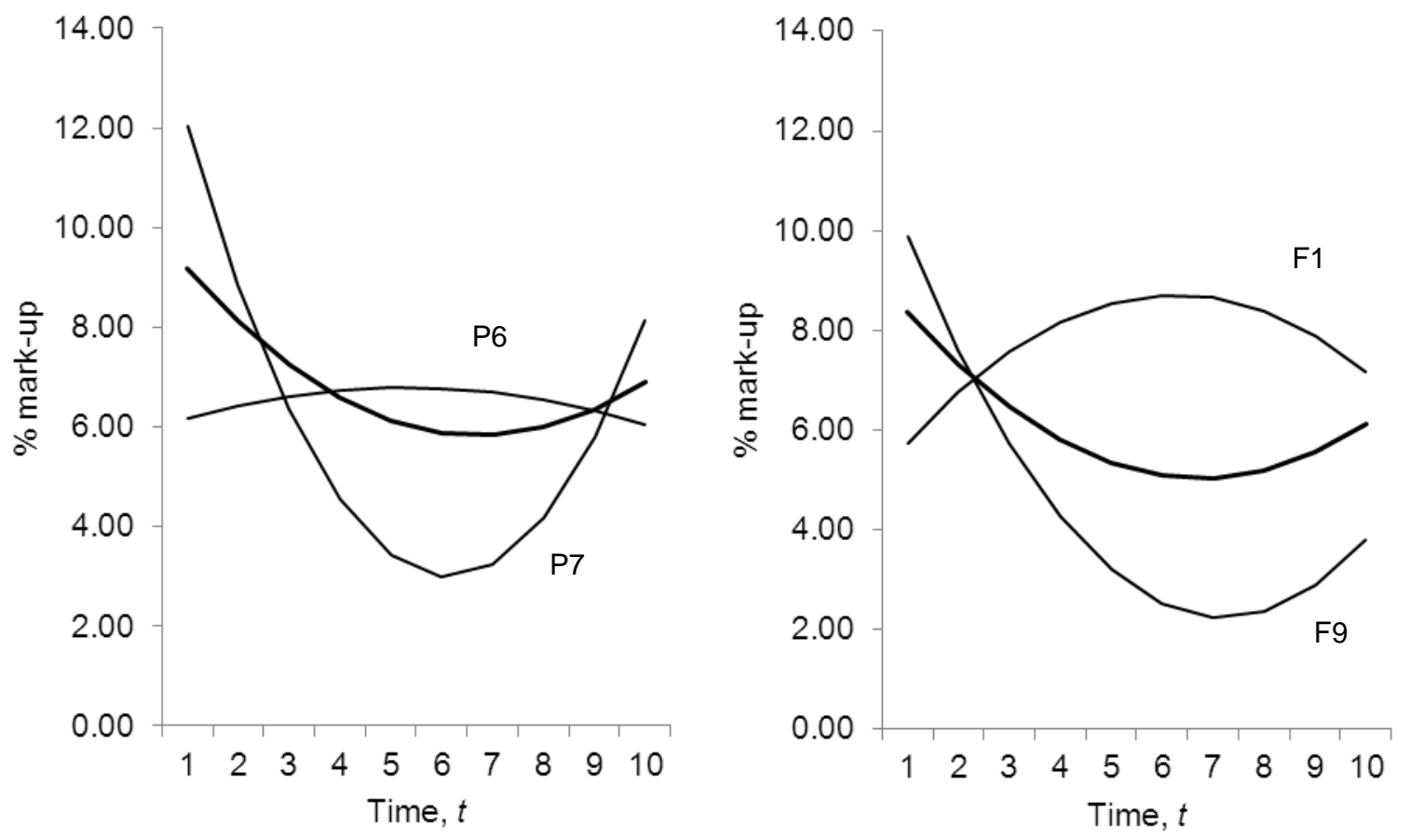

Figure 2: Subject-specific predicted profiles over time (Subjects P6 and P7 in partial information feedback group, and Subjects F1 and F9 in full information feedback group for scenario $S=1$, and the corresponding population-average predicted profiles are in thicker solid lines)

The above empirical results demonstrate that learning occurs through recurrent bidding among the inexperienced bidders. The individual bidders' learning trends are reflected in the variations of their bids over time in consideration of the feedback information conditions and their bidding success in the preceding round. Although there is insignificant variability between bidders in response to the feedback information conditions (i.e., the insignificant random effect of information feedback group, $G$ ), this predictor variable does affect all individual bidders in the samples involved as a whole. The insignificance can be partly explained by the fact that the partial or full information feedback condition was considered adequate by the individual bidders concerned, and did not cause significant variations in their responses since they all have access to winning bids in both information feedback conditions. There is evidence in the literature that the critical feedback information is the winning bids and bidders tend to base their bids on the winning bids (Engelbrecht-Wiggans and Katok, 2008; Neugebauer and Perote, 2008). Nonetheless, the results show that the learning curve of each individual bidder is unique, and that bidders in the full information feedback group are generally more competitive than those in partial information feedback group.

The best-fit LMM and the predicted individual bidders' mean MUP profiles clearly have implications for both clients and contractors. For clients, they should consider providing adequate bidding feedback information in their procurement policy in order to obtain competitive bid prices. Here, there is evidence that full information feedback condition would lead to lower average bids. Also, clients may consider excluding bidders with high bidding success rate in their tenderer list in attempts to enhance efficiency of their procurement process, given that this group of bidders are likely to submit less competitive bids. The predicted individual bidders' mean MUP profiles, on the other hand, provide an individual bidder concerned with an insight into its bidding competitiveness over time. In addition, the proposed 
model has many potential uses in competitor analysis, as part of a more informed approach in identifying key competitors, and as a basis for formulating bidding strategies.

\section{Conclusions}

This paper presents a statistical model on inexperienced individual bidders' learning in recurrent construction bidding under partial and full information feedback conditions. The predictor variables in the best-fit linear mixed model are: time factor, information feedback conditions and bidding success rate in the preceding round. The results show nonlinearity and curvature in the bidders' learning curves. Their learning curves follow a decreasing trend with more competitive bids at the start-up learning phase before an increasing trend with less competitive bids after a period of time for both information feedback conditions. There is an absence of steady-state learning phase among the bidders, suggesting they were in a continual process of learning and yet to reach optimal bidding strategy. Also, all bidders are generally less competitive in time periods after a winning bid with lower average bids submitted by those in the full information feedback group. The model has captured the existence of heterogeneity across bidders with individualspecific parameter estimates that demonstrate the uniqueness of individual bidders' learning curves in recurrent bidding. The study found partial support to H1, i.e. inexperienced bidders in some instances become more competitive over time through learning in recurrent bidding, but not always. In addition, the study did not find that the learning curve of inexperienced bidders contained a steady-state learning phase (H2). These findings suggest that the bidders' competitiveness is affected by changes in their situational conditions at the time of bidding, and that the variations in their bids are expected to continue for a period of time before they attain optimal bidding strategy via learning from their experiences. The implication to construction clients is that consideration needs to be given to the level of contractors' experience and the changes in the market place in formulating their procurement strategies in order to obtain competitive bid prices.

This study found that partial and full information feedback conditions have an impact on inexperienced bidders' learning in recurrent bidding (H3) in that lower average bids were submitted by bidders subjected to full information feedback condition. Given the fact that information feedback conditions in construction bidding vary between clients, ranging from no feedback to full information feedback condition, the findings advocate for adequate bidding feedback information in clients' procurement design to facilitate learning among contractors, which may in turn lead to increased competitiveness in their bids. The findings also show that there is significant heterogeneity across inexperienced individual bidders' learning in recurrent bidding (H4). This finding is important to practice because it indicates that individual bidders' bidding behavior is dependent on many firm-specific characteristics (e.g. a firm's relative efficiency in terms of management skills; the quality of its output), including some that are unobservable by their competitors.

The main limitation of this study is the use of experimental dataset with student subjects in the modelling attempt. It is, however, recognized that experimental dataset is suitable in this context in exploring the specific types of learning trends among inexperienced (student) bidders under different information feedback conditions. This would overcome the ambiguity inherent in field data through active manipulation in an experimental setting, and the possible data contamination problem associated with experienced bidders. Future investigations may use field datasets consisting of both experienced and inexperienced bidders (i.e., new and existing bidders in a particular construction market), with the aim of establishing specific types of learning trends. This suggested future study can be seen as attempts to validate the present findings. Ideally, the field datasets should cover a reasonably long period of time in order to detect whether there is so-called a steady-state learning phase among bidders. As demonstrated here, the linear mixed 
modelling technique could be used to obtain the individual-specific learning trends in a relatively parsimonious manner. In addition, future work should consider all the three common feedback information conditions in construction bidding, to establish the extent to which bidders' learning is affected by varying information feedback conditions, and thus to establish the ideal level of bidding feedback information. This may aid in improving efficiency in construction contracting by providing adequate bidding feedback information to contractors to facilitate their learning, which governs contractors' competitiveness in recurrent bidding.

\section{References}

Cason, T.N. and Friedman, D., 1999. Learning in a laboratory market with random supply and demand. Experimental Economics, 2(1), pp.77-98. doi: http://dx.doi.org/10.1023/A:1009981800289

De Neufville, R., Lesage, Y. and Hani, E.N., 1977. Bidding models: effects of bidders' risk aversion. Journal of the Construction Division, 103(1), pp.57-70.

Dyer, D., Kagel, J.H. and Levin, D., 1989. A comparison of naive and experienced bidders in common value offer auctions: A laboratory analysis. The Economic Journal, pp.108-15. doi: http://dx.doi.org/10.2307/2234207

Drew, D.S. and Fellows, R.F., 1996. Feedback in construction contract bidding. Construction Modernization and Education: Proc., CIB Int. Conf., October 21-24, Chang, W.P. ed. Beijing: China Architectural and Building Press.

Dufwenberg, M. and Gneezy, U., 2002. Information disclosure in auctions: an experiment. Journal of Economic Behavior and Organization, 4(84), pp.431-44. doi: http://dx.doi.org/10.1016/S0167-2681(01)00235-9

Egemen, M. and Mohamed, A.N., 2007. A framework for contractors to reach strategically correct bid/no bid and mark-up size decisions. Building and Environment, 42(3), pp.1373-85. doi: http://dx.doi.org/10.1016/j.buildenv.2005.11.016

Engelbrecht-Wiggans, R. and Katok, E., 2008. Regret and feedback information in first-price sealed-bid auctions. Management Science, 54(4), pp.808-19. doi: http://dx.doi.org/10.1287/mnsc.1070.0806

Esponda, I., 2008. Information feedback in first price auctions. The RAND Journal of Economics, 39(2), pp.491-508. doi: http://dx.doi.org/10.1111/j.0741-6261.2008.00024.x

Fu, W.K., Drew, D. and Lo, H.P., 2002. The effect of experience on contractors' competitiveness in recurrent bidding. Construction Management and Economics, 20(8), pp.655-66. doi: http://dx.doi.org/10.1080/0144619022000014060

Fu, W.K., Drew, D. and Lo, H.P., 2004. Start-up and steady-state learning in recurrent bidding. Building Research and Information, 32(6), pp.484-96. doi: http://dx.doi.org/10.1080/0961321042000312123

Hsiao, C., 2003. Analysis of Panel Data. 2nd ed. Cambridge, UK: Cambridge University Press. doi: http://dx.doi.org/10.1017/CBO9780511754203

Kagel, J.H. and Levin, D., 2002. Common value auctions and the winner's curse. Oxfordshire: Princeton University Press.

Kortanek, K., Sodeni, J. and Sodaro, D., 1973. Profit analyses and sequential bid pricing models. Management Science, 20(3), pp.396-417. doi: http://dx.doi.org/10.1287/mnsc.20.3.396

Ling, F.Y.Y., 2005. Global factors affecting margin-size of construction projects. Journal of Construction Research, 6(01), pp.91-106. doi: http://dx.doi.org/10.1142/S1609945105000274

Lo, H.P., Drew, D. and Fu, W.K., 2000. A handbook of feedback information for construction contract bidding. In: Serpell, A., ed. Information and communication in construction procurement: CIB W92 procurement system symposium. Santiago, Chile, 24-27 April, pp.15-27.

Lowe, D.J. and Skitmore, M., 2006. Bidding. In: Lowe, D.J. and Leiringer, R., eds. Commercial Management of Projects: defining the discipline. Oxford, UK: Blackwell Publishing. doi: http://dx.doi.org/10.1002/9780470759509 and doi: http://dx.doi.org/10.1002/9780470759509.ch16

McCaffer, R. and Pettitt, A.N., 1976. Bidding behaviour in project management. The Project Manager, 1(5), pp. 5-8.

Milgrom, P. and Weber, R.J., 1982. The value of information in a sealed-bid auction. Journal of Mathematical Economics, 10(1), pp.105-14. doi: http://dx.doi.org/10.1016/0304-4068(82)90008-8

Ministry of Finance, 2005. Contracts and purchasing procedures. Singapore: Ministry of Finance. 
Neugebauer, T. and Perote, J., 2008. Bidding 'as if risk neutral in experimental first price auctions without information feedback. Experimental Economics, 11(2), pp.190-202. doi: http://dx.doi.org/10.1007/s10683-007$\underline{9166-0}$

Neugebauer, T. and Selten, R., 2006. Individual behavior of first-price auctions: the importance of information feedback in computerized experimental markets. Games and Economic Behavior, 54(1), pp.183-204. doi: http://dx.doi.org/10.1016/i.geb.2005.10.001

New South Wales Government, 2005. Code of Practice for Procurement. Sydney: New South Wales Government.

Ockenfels, A. and Selten, R., 2005. Impulse balance equilibrium and feedback in first price auctions. Games and Economic Behavior, 51(1), pp.155-70. doi: http://dx.doi.org/10.1016/j.geb.2004.04.002

Oo, B.L., Drew, D. and Lo, H.P., 2007. Applying a random-coefficients logistic model to contractors' decision to bid. Construction Management and Economics, 25(4), pp.387-98. doi: http://dx.doi.org/10.1080/01446190600922552

Oo, B.L., Drew, D. and Lo, H.P., 2008. Heterogeneous approach to modelling the contractors' decision-to-bid strategies. Journal of Construction, Engineering and Management. 10.1061/(ASCE)0733-9364(2008)134:10(766). doi: http://dx.doi.org/10.1061/(ASCE)0733-9364(2008)134:10(766)

Oo, B.L., Abdul-Aziz, A.R. and Lim, Y.M., 2011. Information feedback and learning in construction bidding. Australian Journal of Construction Economics and Buildings, 11(3), pp.34-44. doi: http://dx.doi.org/10.5130/ajceb.v11i3.2173

Oo, B.L., Drew, D.S. and Lo, H.P., 2010a. Modeling the heterogeneity in contractors' mark-up behavior. Journal of Construction Engineering and Management. 10.1061/(ASCE)CO.1943-7862.0000186. doi: http://dx.doi.org/10.1061/(ASCE)CO.1943-7862.0000186

Oo, B.L., Drew, D. and Runeson, G., 2010b. Competitor analysis in construction bidding using mixed model. Construction Management and Economics, 28(12), pp.1321-29. doi: http://dx.doi.org/10.1080/01446193.2010.520721

Oo, B.L., Ling, F.Y.Y. and Soo, A., 2014. Information feedback and bidders' competitiveness in construction bidding. Engineering, Construction and Architectural Management, 21(5), pp.571-85. doi: http://dx.doi.org/10.1108/ECAM-04-2013-0037

Oo, B.L., Lo, H.P. and Lim, B.T.H., 2012. The effect of bidding success in construction bidding. Engineering, Construction and Architectural Management, 19(1), pp.25-39. doi: http://dx.doi.org/10.1108/09699981211192553

Park, W.R. and Chapin, W.B., 1992. Construction bidding: strategic pricing for profit. New York: John Wiley \& Sons Inc.

Runeson, G., 2000. Building economics. Geelong: Deakin University Press.

Runeson, G. and Skitmore, M., 1999. Tendering theory revisited. Construction Management and Economics, 17(3), pp.285-96. doi: http://dx.doi.org/10.1080/014461999371493

Selten, R. and Buchta, J., 1999. Experimental sealed-bid first price auctions with directly observed bid functions. In: Budescu, D., Erev I., and Zwick R. eds. Games and Human Behavior: Essays in the Honor of Amnon Rapoport. Mahwah, New Jersey: Lawrenz Associates.

Selten, R. and Stoecker, R., 1986. End behavior in sequences of finite prisoners' dilemma supergames: a learning theory approach. Journal of Economic Behavior and Organization, 7, pp.47-70. doi: http://dx.doi.org/10.1016/01672681(86)90021-1

Shash, A.A., 1993. Factors considered in tendering decisions by top UK contractors. Construction Management and Economics, 11(2), pp.111-18. doi: http://dx.doi.org/10.1080/01446199300000004

Skitmore, M., 1991. The construction contract bidder homogeneity assumption: An empirical test. Construction Management and Economics, 9(5), pp.403-29. doi: http://dx.doi.org/10.1080/01446199100000032

Skitmore, M. and Runeson, G., 2006. Bidding models: testing the stationarity assumption. Construction Management and Economics, 24(8), pp.791-803. doi: http://dx.doi.org/10.1080/01446190600680432

Soo, A. and Oo, B.L., 2010. The effect of information feedback in construction bidding. Australasian Journal of Construction Economics and Building, 10(1/2), pp.65-75. doi: http://dx.doi.org/10.5130/ajceb.v10i1/2.1589

Verbeke, G., and Molenberghs, G., 2000. Linear Mixed Models for Longitudinal Data. New York: Springer. 